TITLE:

\title{
How do socio-ecological factors shape culture? Understanding the process of micro-macro interactions
}

\section{$\operatorname{AUTHOR}(\mathrm{S}):$}

Uchida, Yukiko; Takemura, Kosuke; Fukushima, Shintaro

\section{CITATION:}

Uchida, Yukiko ... [et al]. How do socio-ecological factors shape culture? Understanding the process of micro-macro interactions. Current opinion in psychology 2020, 32: 115-119

\section{ISSUE DATE:}

2020-04

URL:

http://hdl.handle.net/2433/245210

\section{RIGHT:}

(c) 2020. This manuscript version is made available under the CC-BY-NC-ND 4.0 license

http://creativecommons.org/licenses/by-nc-nd/4.0/; The full-text file will be made open to the public on 1 April 2021 in accordance with publisher's 'Terms and Conditions for Self-Archiving'; この論文は出版社版でありません。引用の際に は出版社版をご確認ご利用ください。; This is not the published version. Please cite only the published version. 
Special Issue on Socio-Ecological Psychology in Current Opinion in Psychology

How do socio-ecological factors shape culture? Understanding the process of micro-macro interactions

\author{
Yukiko Uchida* \\ Kokoro Research Center, Kyoto University \\ 46 Yoshida Shimoadachi-cho, Sakyo-ku, Kyoto, Japan 606-8501 \\ uchida.yukiko.6m@kyoto-u.ac.jp \\ Kosuke Takemura \\ Faculty of Economics, Shiga University \\ 1-1-1 Banba, Hikone, Shiga, Japan 522-8522 \\ Shintaro Fukushima \\ School of Arts and Sciences, Tokyo Woman's Christian University \\ 2-6-1 Zempukuji, Suginami-ku, Tokyo, Japan 167-8585
}

*Correspondence Author 


\section{Abstract}

Socio-ecological environments produce certain psychological functions that are adaptive for survival in each environment. Past evidence suggests that interdependence-related psychological features are prevalent in East Asian cultures partly due to the history of "ricecrop farming" (vs. herding) in those areas. However, it is unclear how and why certain functional behaviors required by the socio-ecological environment are sublimated to become cultural values, which are then transmitted and shared among people. In this paper, we conceptually review the works examining various macro sharing processes for cultural values, and focus on the use of multilevel analysis in elucidating the effect of both macro and individual level factors. Uchida et al.'s study (2019) suggests that collective activities at the macro level (community-level), which is required by a certain socio-ecological environment, promote interdependence not only among farmers but also non-farmers. The multilevel processes of how psychological characteristics are construed by macro factors will be discussed.

Keywords; socio-ecological environment, culture, collective activity hypothesis, multilevel analysis 


\section{Introduction}

A multitude of cross-cultural studies in psychology have shown that psychological functions vary largely across different cultural contexts. For example, interdependence (e.g., seeking harmony) and holistic thinking styles are more prevalent in East Asian cultural contexts, while independence (e.g., seeking uniqueness) and analytic thinking styles are prevalent in North American/European cultural contexts [1, 2]. Expounding on past research, current studies in cultural psychology seek to elucidate factors that underlie such cultural differences [e.g., Ref. 3].

\subsection{Culture and the Socio-ecological approach}

One's socioeconomic/ecological environment is a key factor in shaping psychological and behavioral functions for the purpose of survival and adaptation in that given environment. For example, farming labor affords collective decision making and holistic thinking styles, while herding labor affords independent decision-making processes and analytic thinking styles (see Refs. [4, 5, 6, 7, 8]). Furthermore, recent evidence suggests that there are sizable differences depending on the type of farming. Specifically, rice-based agriculture promotes interdependence because it requires greater cooperation within the community compared to wheat-based agriculture $[9,10,11]$. Thus, the socio-ecological environment allows us to differentiate psychological and 
behavioral functions of societies in a more fine-grained manner beyond the traditional dichotomy of “East vs. West” (see Ref. [12]).

\subsection{Culture, as a macro process, beyond individuals}

However, the current status of socio-ecological research does not adequately explain how psychological and behavioral functions are shared among members of a community. Some ecologically adaptive psychological/behavioral functions are acquired individually (such as through individual learning based on personal experiences) rather than socially [13]. However, recent studies suggest that people, including peripheral members of a community, share the same psychological/behavioral functions of members who directly engage in ecology-related occupations or activities, outside of their own personal experiences. For example, Uskul et al. [6, 7, 14] showed that holistic thinking styles were higher even for family members living in farming communities (e.g., wives and children of farmers), who did not actively engage in farming. Similarly, Uchida et al. [15] demonstrated that non-farmers living in farming communities were more likely to be interdependent than those living in other areas. In addition, research from China showed that students who came from farming communities displayed holistic thinking styles, despite not engaging in farming activities themselves [9]. Thus, psychological 
tendencies can be shared among members of a cultural group, even if there exist individual differences in their connections to specific socio-ecological conditions. In other words, socio-ecological factors affect psychological tendencies not only at the individual level, but also at the macro level.

\subsection{Multilevel approach}

To empirically investigate how psychological/behavioral functions are shared among community members, the consideration of both individual and macro-level phenomenon is needed [16]. As people living in the same areas share common socioecological environments (e.g., climate), single level analyses (analyzing either individuallevel factors or macro-level factors) might condense both compositional and contextual effects of a phenomenon, discounting important information that could have been gleaned by a multilevel analysis. Particularly, the compositional effect explains how personal characteristics affect behaviors or psychological tendencies at the individual-level, while the contextual effect explains how socio-ecological environments (macro-level factors) affect individual behaviors or psychological tendencies at the macro level [17]. Unlike single-level analyses, multilevel analyses of data with nested structure allows the differentiation of effects into both the individual and macro levels [18]. In past cultural 
psychology literature, Uchida et al. [15] collected data from more than 7,000 individuals from approximately 400 communities, and statistically separated the macro-level (community-level) and the individual-level effects. Similarly, Fukushima et al. [19] demonstrated that trust toward community members has a positive individual-level effect and a negative community-level effect on subjective well-being. Takemura et al. [20] also demonstrated that economic wealth is more positively associated with independence at the macro level than the individual level. The existence of these contextual effects (e.g., individuals living in wealthy areas are likely to be independent even when they themselves are not wealthy) suggests that socio-ecological conditions may affect psychological functions at the macro level through social sharing among individuals. It is noteworthy that macro-level factors that originated from a given socio-ecological environment can become its own "culture" that is shared among members through a shared meaning system. Consequently, cultural processes (e.g., social learning, social norms, and shared meaning systems) play unique roles beyond individual factors, which cannot be solely explained by individual-level characteristics.

This begets the questions: (1) how are psychological functions shared among the members of a community and (2) what is the macro learning process? In the next sections, 
we review how "macro culture" is shared among community members, through norm creation and transmission, collective activities, and collective memories.

\section{How is "macro culture" shared?}

\subsection{Norm creation and transmission as with culture of honor}

Cultural norm creation through social interactions is one form of the macro learning process. Nisbett and Cohen's famous work [5] suggested that "culture of honor” related psychological tendencies (e.g., justified anger after receiving insults) are associated with a local history of herding in the Southern regions of the US.

Historically, herders had to protect their economic assets (e.g., cows) from potential thieves by themselves. In order to avoid such risk, herders had to build a reputation as a tough man by reacting aggressively to threats such as insults, thereby defending their honor from each other. Thus, through repeated social interactions, they have collectively created a shared norm that values honor in a man. While the risk of stealing is mitigated in the modern herding context, the code of honor among the people in Southern regions of the US still remains as a self-sustaining system that regulates community members' behaviors. This culture of honor is likely manifested in social interactions among 
members of these communities through small talk (e.g., "Hey, do you know? Bob got furious after getting insulted from Sam, and he hit Sam strongly!”) that carry evaluations (e.g., “Oh, Bob is a man”), or public cultural products [21, 22, 23] such as movies (e.g., showing physically strong man as a hero). These interactions occur between herders and non-herders in a herding community, through joint activities such as Sunday church services (“collective activity” explained in the next section).

Norm creation exists hand in hand with norm transmission, where education plays an important role in the continual adoption of the created norm among newer members of the community. Nisbett and Cohen [5] suggested that boys in Southern part of the US were taught by family members to protest against insult, and were allowed to use force to protect themselves. Also, children in herding communities were more likely to feel the pain of others being ostracized than children in farming communities [14]. Children learn cultural values required in their cultural context through educational textbooks [24], picture books [25] and through social interactions with their parents [26] or with peers [27]. Adults acquire cultural values through social interaction with the members of their cultural communities, such as regional areas that share socioeconomic environments, as well as group organizations (e.g., companies) that share 
collective goals. They can learn cultural values from their peers' behavior [e.g., Ref.

$28]$, which is further reinforced through communication [29, 30].

2.2 Macro-process of accruing socio-ecologically afforded values: collective activity hypothesis

Cultural values are also shared through collective activities. As we described in the previous section, people share norms and use reputation systems in social interactions, and these interactions are likely to happen via participation in collective activities. Our previous work [15] drew from the processes within ecologically connected local communities and discussed how people acquire certain types of behavioral/psychological functions and shared cultural values through engaging in collective activities.

Uchida et al.’s paper [15] questioned why non-farmers in farming areas became more interdependent without personally engaging in farming activities as shown by Talhelm et al. [9]. According to the "collective activity hypothesis," we predicted that the frequency and prevalence of collective activities, including both socio-economic (e.g., maintaining irrigation systems) and other non-directly related activities (e.g., town meetings and festivals), foster interdependence throughout the community. This is 
especially true in farming communities (rice-cropping in Japan), where participation rates in such activities are higher than fishing or other communities. Through participating in such collective activities, people are able to create shared norms or rules to regulate their behaviors as mentioned above in the cultural norm creation and transmission process [31]. These activities are attended by both farmers and non-farmers, as traditional rice-cropping in Japan is labor intensive [9, 32, 33].

For communities to have such collective activities, coordination and mutual trust are required among its participants. In the process, people depend on implicit trust inferred through the reputation of each person's contribution to the community [34, 35]. It becomes risky if they receive negative evaluations from others in their ingroup, since a bad reputation might lead to social exclusion [36, 37]. The avoidance of such a risk highlights their social concerns, which is one aspect of interdependence [38, 39].

In accordance with this prediction, Uchida et al. [15] analyzed the data $(\mathrm{N}=7,295)$ collected in 412 Japanese communities (approximately 100 households from each community) and conducted a multilevel analysis to examine both macro-level effects (living in a farming area) and individual-level effects (engaging in farming/agricultural activities). Their findings revealed that the ratio of farmers in the community (macrolevel factor) promoted interdependence above and beyond engagement in farming 
(individual-level factor), and this contextual effect was mediated by participation in

collective activities (including non-farmers) at the macro-level. This suggests that a shared macro-level culture exists among farming areas, which includes farmers and nonfarmers.

\subsection{Cultural transmission through collective memory}

Lastly, the collective memory of a culture is an important part of the macro sharing process. Collective memories transmit and share collective norms or customs among communities, including one's family and organization. It consists of "publicly available symbols maintained by society” and/or “individual memories shared by members of a community that bear on the collective identity of that community” [p 439, [40] see Refs. [41, 42, 43].

For the former, cultural memory is shaped by cultural products, such as narrative stories or music shared during collective activities, passed down throughout history via intergenerational transmission. Festivals and rituals serve as reminders of the community’s history and identity. It maintains their identity and guides the actions of members belonging to a certain group (nation, community, or family), through 
accessing their shared narratives, which reinforces group membership and strengthens future decision making that perpetuates the collective memory.

The latter aspect suggests that collective memory is constructed through the reciprocal and dynamic interactions between individuals in a community and their attitudes and behaviors toward each other. Conversations among these members reinforce their collective memories, which contribute to the construction of shared realities $[44,45,46]$.

\section{Conclusion}

Culture is a macro phenomenon that is maintained through the psychological output and behaviors of individuals under specific social settings. Individuals construct macro-level norms or notions by inferring from each other's output. Hence, unpacking the processes behind this mutual construction of culture is important. We highlight the necessity for culturally/socially oriented psychologists to elucidate how socioecologically driven psychological functions become "cultural values”, and how they are subsequently transmitted and shared among people. We promote the use of multilevel analysis as a fitting tool to examine this issue and demonstrate recent works that suggest 
several processes to foster culturally shared macro-level phenomena, such as

participation in collective activities or sharing collective memory through interpersonal

communication. 


\section{References}

*of special interest

**of outstanding interest total $10 \%$

[1] Markus HR, Kitayama S: Culture and the self: Implications for cognition, emotion, and motivation. Psychol Rev 1991, 98:224-253.

[2] Nisbett RE, Peng K, Choi I, Norenzayan A: Culture and systems of thought: holistic versus analytic cognition. Psychol Rev 2001, 108: 291-310.

[3] Tominaga H, Uchida Y, Miyamoto Y, Yamasaki T: Negative affect during a collective (but not an Individual) task is associated with holistic attention in East Asian cultural context. Front Psychol, 2017, 8:1283.

[4] Berry JW: Independence and conformity in subsistence-level societies. J Pers Soc Psychol, 1967, 7:415-418.

[5] Nisbett RE, Cohen D: Culture of Honor: The Psychology of Violence in the South. Boulder, CO: Westview; 1996.

[6] Uskul AK, Kitayama S, Nisbett RE: Ecocultural basis of cognition: Farmers and fishermen are more holistic than herders. Proc Natl Acad Sci USA, 2008, 105: 8552-8556. *[7] Uskul AK, Over H: Responses to social exclusion in cultural context: Evidence from farming and herding communities. J Pers Soc Psychol, 2014, 106:752-771.

A series of studies suggested that the economic systems shape how their members interact with others and how they response to social exclusion.

[8] Thomson R, Yuki M, Talhelm T, Schug J, Kito M, Ayanian A, Becker J, Becker M, Chiu CY, Choi H, et al: Relational mobility predicts social behaviors in 39 countries and is tied to historical farming and threat. Proc Natl Acad Sci USA, 2018, 115: 7521-7526.

[9] Talhelm T, Zhang X, Oishi S, Shimin C, Duan D, Lan X, Kitayama S: Large-scale psychological differences within China explained by rice versus wheat agriculture. Science, 2014, 344: 603-608.

[10] Dong X, Talhelm T, Ren X: Teens in rice county are more interdependent and think more holistically than nearby wheat county. Soc Psychol Pers Science, 2018. doi: $10.1177 / 1948550618808868$

[11] Talhelm T, Zhang X, Oishi S: Moving chairs in Starbucks: Observational studies find rice-wheat cultural differences in daily life in China. Science Adv, 2018, 4: eaap8469.

[12] Hamamura T, Takemura K: Common view by whom? Asian J Soc Psychol, 2018, 21: 331-335.

[13] Tooby J, Cosmides L: The psychological foundations of culture. In Barkow JH, Cosmides L, Tooby J (Eds.), The Adapted Mind: Evolutionary Psychology and the 
Generation of Culture. 1992, Oxford University Press; New York, 19-136.

[14] Over H, Uskul AK: Culture moderates children's responses to ostracism situations. J Pers Soc Psychol, 2016, 110: 710-724.

**[15] Uchida Y, Takemura K, Fukushima S, Saizen I, Kawamura Y, Hitokoto H, Koizumi N, Yoshikawa S: Farming cultivates a community-level shared culture through collective activities: Examining contextual effects with multilevel analyses. J Pers Soc Psychol, 2019, 116:1-14.

The paper addresses the multilevel processes of how psychological characteristics (interdependence in Japan) are shared in farming areas through collective activities.

*[16] Kashima Y, Bain PG, Perfors A: The psychology of cultural dynamics: What is it, what do we know, and what is yet to be known? Ann Rev Psychol, 2019, 70: 499-529.

The paper reviewed the literature on cultural dynamics (micro-macro dynamics) and discuss the future directions.

[17] Hauser RM: Context and consex: a cautionary tale. Am J Sociol, 1970, 75: 645-664. [18] Uchida Y, Ogihara Y, Fukushima S: Cultural construal of wellbeing - Theories and empirical evidence. In Glatzer W, Camfield L, Moller V, Rojas M (Eds.), Global Handbook of Quality of Life: Exploration of Well-Being of Nations and Continents, 2015, Springer; Netherlands, 823-837.

*[19] Fukushima S, Takemura K, Uchida Y, Asano S, Okuda N: Trust within a community is a double-edged sword: Trust has a positive individual-level effect and a negative contextual effect on subjective well-Being. Psychologia, in press.

With the multilevel analysis, the paper examined that community trust had a positive effect on subjective well-being at the individual level and a negative contextual effect at the community level.

[20] Takemura K, Hamamura T, Guan Y, Suzuki S: Contextual effect of wealth on independence: An examination through regional differences in China. Front Psychol, 2016: 7, 384.

[21] Morling B, Lamoreaux M: Measuring culture outside the head: A meta-analysis of individualism—collectivism in cultural products. Pers Soc Psychol Rev, 2008, 12: 199221.

[22] Lamoreaux M, Morling B: Outside the head and outside individualism-collectivism: Further meta-analyses of cultural products. J of Cross-Cult Psychol, 2012, 43: 299-327. [23] Markus HR, Uchida Y, Omoregie H, Townsend SS, Kitayama S: Going for the gold: Models of agency in Japanese and American contexts. Psychol Sci, 2006, 17: 103-112. [24] Imada T: Cultural narratives of individualism and collectivism: A content analysis of textbook stories in the United States and Japan. J Cross-Cult Psychol, 2012 , 43: 576-591. 
[25] Tsai JL, Louie J, Chen EE, Uchida Y: Learning what feelings to desire: Socialization of ideal affect through children's storybooks. Pers Soc Psychol Bull, 2007, 33: 17-30.

[26] Senzaki S, Masuda T, Takada A, Okada H: The communication of culturally dominant modes of attention from parents to children: a comparison of Canadian and Japanese parent-child conversations during a joint scene description task. PLoS One, 2014, 11: e0147199.

[27] Mesoudi A, Magid K, Hussain D: How do people become W.E.I.R.D.? Migration reveals the cultural transmission mechanisms underlying variation in psychological processes. PLoS One, 2016, 11: e0147162.

[28] Kashima Y, Wilson S, Lusher D, Pearson LJ, Pearson C: The acquisition of perceived descriptive norms as social category learning in social networks. Soc Netw, 2013, 35:711719.

[29] Kashima Y: Maintaining cultural stereotypes in the serial reproduction of narratives. Pers Soc Psychol Bull, 2000, 26:594-604.

[30] Lyons A, Kashima Y: How are stereotypes maintained through communications? The influence of stereotype sharedness. J Pers Soc Psychol, 2003, 85: 989-1005.

[31] Ginges J, Hansen I, Norenzayan A: Religion and support for suicide attacks. Psychol Sci, 2009, 20: 224-230.

[32] Hara H, Kumagai H: Non-farmers' willingness of participation in the maintenance and management of irrigation canals: A case study in the central area, Toyama prefecture. J Rural Plann Assoc, 2008, 26: 407-415.

[33] Hasegawa A: Space structure of the rural community. Mem Inst Soc Sci. Meiji Univ, 1969, 7: 243-274.

[34] Feinberg M, Willer R, Schultz M: Gossip and ostracism promote cooperation in groups. Psychol Sci, 2014, 25: 656-664.

[35] Milinski M, Semmann, Krambeck HJ: Reputation helps solve the 'tragedy of the commons'. Nature, 2002, 415: 424-426.

[36] Mifune N, Hashimoto H, Yamagishi T: Altruism toward in-group members as a reputation mechanism. Evol Hum Behav, 2010, 31:109-117.

[37] Roos P, Gelfand M, Nau D, Carr R: High strength-of-ties and low mobility enable the evolution of third-party punishment. Proc R Soc Lond B Biol Sci, 2014, 281: 20132661.

[38] Hashimoto H, Yamagishi T: Two faces of interdependence: Harmony seeking and rejection avoidance. Asian J Soc Psychol, 2013, 16:142-151.

[39] Hashimoto H, Yamagishi T: Duality of independence and interdependence: An adaptationist perspective. Asian J Soc Psychol, 2016, 19: 286-297. 
[40] Hirst W, Yamashiro JK, Coman A: Collective memory from a psychological perspective. Trends Cogn Sci, 2018, 22: 438-451.

[41] Hirst W, Manier D: Towards a psychology of collective memory. Memory 2008, 16:183-200.

[42] Wertsch JV, Roediger III, HL: Collective memory: Conceptual foundations and theoretical approaches. Memory, 2008, 16: 318-326.

[43] Olick, J.K. (1999) Collective memory: the two cultures. J Sociol Theory Relig, 17, 333-348

*[44] Coman A, Momennejad I, Drach RD, Geana A: Mnemonic convergence in social networks: The emergent properties of cognition at a collective level. Proc Natl Acad Sci USA, 2016, 113: 8171-8176.

The study reported the formation of collective memories in laboratory-created communities.

[45] Hirst W, Coman A: Building a collective memory: the case for collective forgetting. Curr Opin Psychol, 2018, 23: 88-92.

[46] Momennejad I, Duker A, Coman A: Bridge ties bind collective memories. Nat Commun, 2019, 10:1578. 